\title{
QUEEN'S
UNIVERSITY
BELFAST
}

\section{Evaluation of infilled frames: an updated in-plane-stiffness macro- model considering the effects of vertical loads}

Campione, G., Cavaleri, L., Macaluso, G., Amato, G., \& Di Trapani, F. (2015). Evaluation of infilled frames: an updated in-plane-stiffness macro-model considering the effects of vertical loads. Bulletin of Earthquake Engineering, 13(8), 2265-2281. https://doi.org/10.1007/s10518-014-9714-x

Published in:

Bulletin of Earthquake Engineering

Document Version:

Peer reviewed version

Queen's University Belfast - Research Portal:

Link to publication record in Queen's University Belfast Research Portal

Publisher rights

The final publication is available at Springer via http://dx.doi.org/10.1007/s10518-014-9714-x

\section{General rights}

Copyright for the publications made accessible via the Queen's University Belfast Research Portal is retained by the author(s) and / or other copyright owners and it is a condition of accessing these publications that users recognise and abide by the legal requirements associated with these rights.

Take down policy

The Research Portal is Queen's institutional repository that provides access to Queen's research output. Every effort has been made to ensure that content in the Research Portal does not infringe any person's rights, or applicable UK laws. If you discover content in the Research Portal that you believe breaches copyright or violates any law, please contact openaccess@qub.ac.uk. 


\section{Evaluation of infilled frames: an updated in-plane-stiffness macro-model considering the effects of vertical loads}

L. Cavaleri*, G. Campione, G. Macaluso,

Dipartimento di Ingegneria Civile, Ambientale, Aerospaziale e dei Materiali (DICAM), University of Palermo, 90128 Palermo, Italy.

G. Amato

School of Planning Architecture and Civil Engineering, Queen's University Belfast, UK

Author's accepted manuscript.

The final publication is available at Springer via http://dx.doi.org/10.1007/s10518-014-9714-x

Keywords: Infilled frames, in-plane behaviour, equivalent diagonal pin-jointed strut model, vertical load influence

Abstract The influence of masonry infills on the in-plane behaviour of RC framed structures is a central topic in the seismic evaluation and retrofitting of existing buildings. Many models in the literature use an equivalent strut member in order to represent the infill but, among the parameters influencing the equivalent strut behaviour, the effect of vertical loads acting on the frames is recognized but not quantified. Nevertheless a vertical load causes a non negligible variation in the in-plane behaviour of infilled frames by influencing the effective volume of the infill. This results in a change in the stiffness and strength of the system. This paper presents an equivalent diagonal pinjointed strut model taking into account the stiffening effect of vertical loads on the infill in the initial state. The in-plane stiffness of a range of infilled frames was evaluated using a finite element model of the frame-infill system and the cross-section of the strut equivalent to the infill was obtained for different levels of vertical loading by imposing the equivalence between the frame containing the infill and the frame containing the diagonal strut. In this way a law for identifying the equivalent strut width depending on the geometrical and mechanical characteristics of the infilled frame was generalized to consider the influence of vertical loads for use in the practical 
applications. The strategy presented, limited to the initial stiffness of infilled frames, is preparatory to the definition of complete non-linear cyclic laws for the equivalent strut.

*Corresponding author, E-mail: liborio.cavaleri@unipa.it 


\section{Introduction}

Infills, although considered non-structural members, radically modify the in-plane RC frame response under in-plane lateral load. The fact is that the in-plane stiffness of the frame, due to the presence of the infill, can increase up to ten times while the frame strength can grow up to four times, as found by many authors (e.g. Stafford Smith 1968; Cavaleri et al. 2005). Moreover, the interaction between infill and frame may or may not be beneficial to the performance of the structure under a seismic load: while in some cases the global performance could improve, several debates (e.g. NCEER 1994) and experiences in recent earthquakes have demonstrated that an otherwise well-designed structure could collapse due to low seismic excitation if infills are not uniformly distributed, both horizontally and vertically.

The in-plane stiffness and strength of an infilled frame are affected by several variables such as the geometrical and mechanical properties of the infill and frame members, details of frame members, frame-infill stiffness ratio, out-of-plane infill loading (here not considered), workmanship and construction techniques and vertical loads transferred from the frame to the infill.

One of the approaches for simulating the in-plane-influence of infill consists in replacing the infill itself with one or more equivalent struts made of the same material as the infill (macro-modelling), see original works by Asteris (2003), Cavaleri and Papia (2003), Crisafulli and Carr (2007), Zhai et al. (2011), Chrysostomou and Asteris (2012) and review works by Moghaddam and Dowling 1987, Asteris et al. (2011). Macro-modelling may be advantageous for a number of reasons and especially for design purposes. Moreover, it avoids the computational effort required by the solid/plane finite element modelling of infills (micromodelling).

The micro-modelling approach has been widely used in the literature (e.g. Koutromanos et al. 2011; Manos et al. 2011, 2012; Shing and Stavridis 2014; Asteris and Cotsovos 2012; Asteris et al. 2012, 2013). It provides detailed information on the structural response, for example on local effects on frame members; however, especially in non-linear cases, it requires long computational time and calibration of many parameters. Hence the macromodel approach may be an advantage, but at the same time the importance of the micro model approach is not under discussion. 
A complete definition of the equivalent strut model requires (a) fixing the initial axial elastic properties (Young modulus and cross-section), (b) a law for the variation of the mechanical properties during cyclic loading, (c) the axial strength envelope. The evaluation of the initial elastic properties has a key role for the definition of the cyclic law. For example, Klingner and Bertero (1978), after fixing the thickness and initial elastic modulus of the equivalent strut equal to those of the infill, evaluated the width $\mathrm{w}$ of the equivalent strut by means of the following expressions (Mainstone 1974):

$$
\frac{w}{d}=0.175\left(\lambda h^{\prime}\right)^{-0.4} ; \lambda=\sqrt[4]{\frac{E_{i} t \sin (2 \theta)}{4 E_{f} I_{c} h}}
$$

In Eq. $1 E_{i}$ and $E_{f}$ are respectively the elastic diagonal modulus of the infill and the elastic modulus of the concrete, $I_{c}$ is the moment of inertia of the column cross-section; see Fig. 1 for description of symbols.

Similarly to those of Klingner and Bertero, the cyclic laws proposed by Doudoumis e Mitsopoulou (1986) and by Panagiatakos and Fardis (1996) depend on the definition of the initial stiffness of the equivalent strut (elastic loading curve of the strength envelope). The same approach was followed for the definition of the strut cyclic laws proposed by Cavaleri et al. (2005) (Fig. 2) and by Cavaleri and Di Trapani (2014) (Fig. 3). As shown in the works mentioned before, identification of the initial axial stiffness of the equivalent strut is the first step for the definition of a complete cyclic law for the strut itself under axial loading.

The approach for the identification of the strut width used in Eq. 1 is not the only one.

For example, Durrani and Luo (1994), on the basis of the experimental work of Mainstone (1974), proposed the following analytical relation:

$$
\frac{w}{d}=0.32 \sin ^{1.5}(2 \theta)\left(\frac{E_{i} t h^{\prime 4}}{m E_{c} I_{c} h}\right)^{-0.1}
$$

where 


$$
m=6\left(1+\frac{6}{\pi} \operatorname{arctg} \frac{I_{b} h^{\prime}}{I_{c} \ell^{\prime}}\right)
$$

and $I_{b}$ is the moment of inertia of the beam cross-section (see Fig. 1 for description of symbols).

Flanagan and Bennet $(1999,2001)$ based on the results of a number of full-scale clay infilled steel frames tested under in-plane loading proposed to evaluate the width of the strut, $w$, as

$$
w=\frac{\pi}{C \lambda \cos \theta}
$$

$\mathrm{C}$ being an empirical constant varying with the in-plane drift displacement used as an indicator of the limit state of the infill.

A further model for the identification of the width of the equivalent strut taking into account the Poisson's ratio of the infill material was proposed by Papia et al. (2003) and is explained in the next section.

Identification of the in-plane stiffness of an infilled frame is addressed by the actual codes; for example FEMA 356 (2000), in agreement with the strategy adopted by the authors mentioned above, suggests the formula proposed by Mainstone (Eq. 1). Eurocode 8 (2004) confirms the need to take the infill into account but does not suggest a specific model and refers the designer to specialised literature.

As for the effect of vertical loads it is recognized that it modifies the behaviour of infilled frames under in-plane lateral loading. In micro-models the load influence is taken into account by modelling the frame-infill contact area: see Fig. 4. On the other hand in a macro-model the vertical load transferred from frame to infill can only be taken into account by calibrating the strut mechanical response for different levels of vertical loading. However, few authors have quantified this influence.

In (1968) Stafford Smith investigated the influence of a uniformly distributed vertical load imposed on the upper beam of a single storey-single bay steel frame in-plane stiffness and observed a 5 
considerable increase in the in-plane lateral stiffness and strength of the structure. More recently, Valiasis and Stylianides (1989), studying RC frames infilled with brick masonry walls, observed that the presence of a compressive axial load on the columns considerably improved the in-plane lateral strength of the system. Based on these results, Stafford Smith and Valiasis considered the vertical load effect to be conservative and did not take it into account among the variables affecting the evaluation of the cross-section of the equivalent strut. Similar experimental and numerical results were obtained by Manos et al.

(2012), Stylianidis (2012), Valiasis and Stylianides (1989) and Valiasis et al. (1993).

However, while the conclusion that the vertical load effect is conservative can be valid for a single frame, this may not be true for multi-bay, multi-storey frames with non-uniform load distribution since the different stiffness and strength of a single frame may cause torsional and soft-storey effects.

In this paper, a correlation taking into account the vertical load influence on the initial stiffness of a strut equivalent to an infill is proposed. This work integrates the research described in two previous papers: in Papia et al. (2003) a family of curves for estimating the width of the equivalent strut in the absence of vertical loads is provided and in Papia et al. (2004) the mechanism governing the influence of vertical loads on the infilled frame response is analysed. In this paper a family of curves obtained for rectangular infills is presented together with the curves proposed by Amato et al. (2008, 2009) for square infills.

In the next sections the procedure used to obtain the correlation between infill and equivalent strut is described. This procedure couples an analytical calculation of the frame-infill system components with a finite element micro-modelling of the infilled frame system as a whole. The FE model provides the response of a series of infilled frames under horizontal and vertical loads by using contact surface elements governed by the Coulomb friction law to model the transmission of the compressive stresses from the frame to the infill. 


\section{Strategy for the equivalent strut width identification}

The cross-section of the pin-jointed strut equivalent to an infill of a single storey-single bay infilled frame can be identified by imposing the initial stiffness of the system in Fig. 1a to be equal to the initial stiffness of the equivalent braced frame in Fig. 1b. It should be noted that these schemes do not exactly represent a generic frame of a framed structure: the lower beam is assumed to be rigid and thus the bottom ends of the columns in Fig. $1 \mathrm{~b}$ are fully restrained.

This assumption is in agreement with the conclusions of many authors (Mainstone 1971, 1974;

Stafford Smith and Carter 1969) showing that the contribution of infill to the in-plane lateral stiffness of a frame can be obtained by studying the scheme in Fig. $2 b$ as an alternative to the scheme in Fig. 2a.

Denoting as .Di the stiffness of the actual system (Fig. 1a) solved by the Finite Element Method (micro-modelling approach) and as Di the stiffness corresponding to the simplified analytical model (Fig. 1b), their equivalence can be written as

$$
D_{i}=\bar{D}_{i}
$$

When this equivalence is imposed, assuming the thickness of the strut to be the same of the infill and the Young's modulus to be equal to the diagonal elastic modulus of the infill, the width $w$ of the strut can be calculated.

\section{Stiffness of the frame-strut equivalent system}

The in-plane stiffness $D_{i}$ of the scheme in Fig. 1-b, equivalent to the scheme in Fig. 1-a, can be evaluated with good approximation as the sum of the horizontal forces $D_{d}$ and $D_{f}$ to be applied to the schemes in Fig. 3-b and Fig. 3-c, (obtained as the decomposition of the scheme in Fig.1-a) to produce a displacement $\delta=1$ at the beam middle span:

$$
D_{i}=D_{d}+D_{f}
$$


For the scheme in Fig. 3-b the in-plane stiffness $D_{d}$ can be calculated as follows

$$
D_{d}=\frac{k_{d} \cos ^{2} \theta}{1+\frac{k_{d}}{k_{c}} \operatorname{sen}^{2} \theta+\frac{1}{4} \frac{k_{d}}{k_{b}} \cos ^{2} \theta}
$$

$k_{d}, k_{c}$ and $k_{b}$ being the axial stiffness of the diagonal strut, columns and beam respectively:

$$
k_{d}=\frac{E_{d} t w}{d} ; \quad k_{c}=\frac{E_{f} A_{c}}{h^{\prime}} ; \quad k_{b}=\frac{E_{f} A_{b}}{\ell^{\prime}}
$$

In Eq. $8 E_{d}$ and $E_{f}$ are the Young's modulus of the infill along the diagonal direction and the Young's modulus of the concrete used for the frame; $t$ is the thickness of the infill; $A_{c}$ and $A_{b}$ are the column and beam cross-sectional areas; the angle $\theta$ defines the diagonal direction of the strut and $h^{\prime}$ and $\ell^{\prime}$ are the height and length of the frame, see Fig. 1.

In regard to the Young's modulus of the infill along the diagonal direction it should be observed that since the masonry shows an orthotropic behaviour the mechanical characteristics of the equivalent strut can be estimated by combining the masonry elastic moduli along the horizontal and vertical directions as suggested in Jones 1975, or by using the simplified approach discussed by Cavaleri et al. 2014 on the basis of the experimental studies reported in Cavaleri et al. 2012.

The in-plane stiffness of the frame $D_{f}$ in Fig. 3-c, in the case of columns having the same crosssection, can be evaluated as follows

$$
D_{f}=24 \frac{E_{f} I_{c}}{h^{\prime 3}}\left(1-1.5\left(3 \frac{I_{b}}{I_{c}} \frac{h^{\prime}}{\ell^{\prime}}+2\right)^{-1}\right)
$$

$I_{c}$ and $I_{b}$ being the moments of inertia of the column and beam sections respectively. In the case of columns with different cross-sections the mean value of the axial stiffness of the columns can be used. 


\section{Infilled frame stiffness by the refined FE model}

For the evaluation of the in-plane lateral stiffness by means of the micro-model approach, the ADINA software was used. Both the frame and the infill were modelled using plane stress solid elements having four nodes each. The nodes at the base of the columns were fully restrained while three degrees of freedom were assigned to all the other ones. The infill and the frame were modelled by means of elastic homogenous and isotropic materials having elastic modulus Ed and $\mathrm{E} f$ and Poisson's ratio $v d$ and $v$ f respectively.

The frame-infill interaction was modelled by 2D contact surface elements (Bathe and Bouzinov 1997). Each interface element is composed of two contact surfaces, a contactor and a target surface, which may come into contact during the loading process. No tensile strength is associated with the joint and this makes it possible to model the detachment between frame and infill. Because the interaction between frame and infill is strictly dependent on the length of the contact zone, which is influenced by the vertical load, this kind of finite element allows evaluation of the system in-plane lateral stiffness .Di in relation to the vertical load.

With regard to the frame-infill contact surface, the value to assign to the Coulomb friction coefficient has been debated in the literature (Manos et al. 2011, 2012; Stylianidis 2012; Valiasis and Stylianides 1989; Valiasis et al. 1993). However, in some cases it is accepted that a variation in friction coefficient does not modify the overall response of an infilled frame (e.g. Asteris 2008; Fiore et al. 2012) while in other cases it is considered basic (e.g.

Saneinejad andHobbs 1995). Certainly a variation in friction between frame and infill, whose realistic characterization is not simple, though it may leave the overall response unchanged, it can modify the local response, leading to a reduction in the stresses normal to the frame-infill contact surface. This also produces a reduction in the shear stresses on the members. 
For the case analyzed here, considering that values of the Coulomb friction coefficient generally lower than 0.6 can be found in the literature for modelling the frame-infill interface, the value 0.45 was set, being the average of the values most frequently encountered.

The numerical analysis was carried out for different values of mechanical and geometrical properties of the system and for four vertical load levels. For each analysis the in-plane lateral stiffness .Di of the system was calculated as the ratio between the applied horizontal load and the average beam displacement. The horizontal and vertical forces acting on the frame were applied on the initial and final sections of the beam at middle depth, while the vertical load was concentrated on the top nodes of the beam-column joints, as shown in Fig. 7.

\section{Equivalent strut cross-section}

By substituting the value of $D_{i}$ obtained from Eq. 6 in Eq. 5, one obtains

$$
\bar{D}_{i}=D_{d}+D_{f}
$$

Further, by substituting Eq.7 in Eq.10 the ratio $w / d$ can be expressed as a function of the in-plane stiffness $\bar{D}_{i}$ of an infilled frame given by the refined FE model previously described and the bare frame stiffness $D_{f}$ given in Eq. 9:

$$
\frac{w}{d}=\frac{\bar{D}_{i}-D_{f}}{E_{d} t \cos ^{2} \theta}\left(1-\frac{\bar{D}_{i}-D_{f}}{k_{c}}\left(\frac{h^{\prime 2}}{\ell^{\prime 2}}+\frac{1}{4} \frac{k_{c}}{k_{b}}\right)\right)^{-1}
$$

In Eq. $10 D_{f}$ is the in-plane stiffness of a bare frame under the assumption of non-negligible axial deformation. With regard to $\bar{D}_{i}$ different experimental and numerical investigations (see Cavaleri et al 2005, Cavaleri and Di Trapani 2014, Manos et al. 2011, Manos et al. 2012, Valiasis and Stylianides 1989) have shown that the infilled frame deflected shape is flexural.

In agreement with the most widespread tendency in the literature the ratio between the strut width and the strut length is expressed as a function of a parameter $\lambda^{*}$ which takes into account the elastic 
and geometrical features of the system $w / d=f\left(\lambda^{*}\right)$. This function must also take into account the influence of verticals load.

\section{Dimensionless infilled frame parameter $\lambda^{*}$}

The definition of a parameter that defines the ratio $w / d$ to be adopted for the identification of a strut equivalent to an infill, can be obtained by imposing that the difference $\bar{D}_{i}-D_{f}$ on the right hand of Eq. 11 is the infill in-plane stiffness.

Once the Poisson ratio $v_{d}$, the vertical load $F_{V}$ and aspect ratio $\ell / h$ are fixed, the in-plane stiffness of an infill can be calculated using the total stiffness from the finite element simulation $\bar{D}_{i}$ as

$$
D_{d}=\bar{D}_{i}-D_{f}=\psi E_{d} t
$$

where $\psi$ depends on the unknown extension of the frame-infill contact regions influenced by the above quantities. On the other hand, setting

$$
\lambda^{*}=\frac{E_{d}}{E_{f}} \frac{t h^{\prime}}{A_{c}}\left(\frac{h^{\prime 2}}{\ell^{\prime 2}}+\frac{1}{4} \frac{A_{c}}{A_{b}} \frac{\ell^{\prime}}{h^{\prime}}\right)
$$

Eq. 11 can be written in the form

$$
\frac{w}{d}=\frac{1}{\cos ^{2} \theta} \frac{1}{\psi^{-1}-\lambda^{*}}
$$

Eq.14 shows that, for assigned values of $\ell / h, v_{d}$ and $F_{v}$ (on which $\psi$ depends) a family of curves $w / d=f\left(\lambda^{*}\right)$ can be defined. In order to obtain these curves a number of infilled frames characterized by different values of the quantities that define the parameter $\lambda^{*}$ were analysed using the micro-modelling procedure previously described. In this study two different values of the aspect ratio $\ell / h$, namely 1 and 1.5 , and two different values of the Poisson's ratios, $v_{d}=0.15$ and $v_{d}=0.25$, were investigated. The analyses were repeated for four dimensionless vertical load levels: $\varepsilon_{v}=0, \varepsilon_{v}=0.00016, \varepsilon_{v}=0.00032, \varepsilon_{v}=0.00080, \varepsilon_{v}$ being defined as 


$$
\varepsilon_{v}=\frac{F_{v}}{2 A_{c} E_{c}}
$$

$A_{c}$ being the cross section area of the column, $E_{c}$ the Young modulus of the concrete constituting the frame and $F_{v}$ the total vertical load acting on the frame.

\section{Results and design curves}

The analysis of the FE simulations shows that the frame-infill contact surface grows with the vertical load magnitude and that for high level of vertical load the mechanical behaviour of the infill switches from that of a strut element to that of a plate, see Fig. 8. As a consequence for a fixed $\lambda^{*}$ the frame in-plane stiffness and thus the strut dimensionless width $w / d$ grows as a function of $F_{v}$.

In Figs. 9-12 the results of the numerical analyses in terms of ratio $w / d$ versus the parameter $\lambda^{*}$ are plotted for the different infill Poisson's ratio and different levels of vertical load. These results confirm that the close dependence of the strut width on the parameter $\lambda^{*}$, previously shown in Papia et al. (2003) holds in the presence of vertical load.

In order to obtain a useful design tool, the $w / d$ values were fitted by the analytical expression proposed in Cavaleri et al. (2005)

$$
\begin{gathered}
\frac{w}{d}=k \frac{c}{\left(\lambda^{*}\right)^{\beta}} \\
c=0.249-0.0116 v_{d}+0.567 v_{d}^{2} \\
\beta=0.146+0.0073 v_{d}+0.126 v_{d}{ }^{2}
\end{gathered}
$$

$k$ being a coefficient that was not characterized in the above cited work and that takes the effect of vertical load into account. For $k=1$ (no vertical load acting) the function (16) assumes the form proposed in (Papia et al. 2003). 
The numerical investigation carried out in this work showed quite a linear dependence of the coefficient $k$ on vertical load and axial strains of the columns. This relationship can be approximated by the following expression

$$
k=\frac{1}{0.75+0.25 \frac{\ell}{h}}\left[1+\left(18 \lambda^{*}+200\right) \varepsilon_{v}\right]
$$

In Figs. 9-12 the analytical curves provided by Eqs.(16-19) have been plotted. The numerical vs model comparison shows a good agreement for both rectangular and square infills. For sake of completeness the comparison already discussed in Papia et al (2003), between the results of the FE analyses and the analytical curves provided by Eqs. (16-19) when no vertical load is transferred to the infills, is shown in Fig. 10.

In Figs. 14 and 15 the families of analytical curves obtained for different Poisson's ratio and aspect ratio are plotted together. As it can be observed the equivalent strut width $w / d$ increases when the level of vertical load grows. Moreover the Poisson's ratio has a stiffening effect on the in-plane response of the infilled frame.

\section{Conclusions}

In this paper the mechanical behaviour of infilled frames under in-plane loading has been discussed and an analytical law taking into account the influence of vertical load on the characteristics of the pin-jointed diagonal strut equivalent to an infill is proposed.

A numerical investigation on infilled frames having different geometric and mechanical characteristics has been carried out and the results showed the stiffening effect of the vertical load transferred from the frame to the infill. The analyses, carried out using a FE model in which frame and infill are modelled as linear shell elements and the frame-infill interface with link elements working in compression only, have shown that the detachment of the contact surface between frame 
and infill, produced by in-plane loading, decreases when vertical load are transferred to the infill. This produces a stiffening of the structural system.

The study focuses on the initial undamaged stiffness of a frame-infill system, which is of key importance for the correct definition of the cyclic response under seismic loading. This slope influences the strength envelope, in particular the slope of the linear branches of the envelope.

For given infill thickness and material, the characterization of the initial stiffness of the equivalent strut depends only on the identification of the strut width. The dimensionless width $w / d$, in this work is given as a function of a synthetic parameters $\left(\lambda^{*}\right)$, depending on the mechanical parameters of frame and infill. A family of $w / d$ vs $\lambda^{*}$ curves, each one depending on the infill Poisson's ratio and level of mean axial strain produced by the vertical load on the frame columns, has been obtained.

It has also been shown that as the parameter $\lambda^{*}$ increases the corresponding values of $w / d$ can be described by a power law depending on the level of vertical load transferred from the frame to the infill.

These curves provide an effective tool for taking into account the contribution of infills to the global structural stiffness. They allow a quick evaluation of the contribution of the infill to the in-plane stiffness of the generic frame of a framed structure and can be used in any commercial structural analysis software when a simplified approach for the prediction of the response is preferred to a detailed micro-modelling.

Obviously the identification of the initial characteristics of the equivalent strut also needs the identification of the further parameters able to define a complete non-linear law for the strut. In the case of the Pivot model described by Cavaleri and Di Trapani (2014) three further parameters - one for the degradation of stiffness and two for the strength envelope, are sufficient to characterize completely the equivalent strut for seismic analysis. 


\section{References}

ADINA Theory and Modeling Guide - Volume I: Solids \& Structures (2012) ADINA R \& D, Inc. USA

Amato G, Cavaleri L, Fossetti M, Papia M (2008) Infilled frames: influence of vertical load on the equivalent diagonal strut model. Proc. of 14th WCEE, Beijing, China, CD-ROM, Paper 05-01-0479.

Amato G, Fossetti M, Cavaleri L, Papia M (2009) An updated model of equivalent diagonal strut for infill panels. Proc. of Eurocode 8, Perspectives from the Italian standpoint Workshop. Doppiavoce Editor. Napoli, Italy, 119-128.

Asteris PG (2003) Lateral Stiffness of Brick Masonry Infilled Plane Frames. J Struct Eng ASCE 129(8):1071-1079.

Asteris PG (2008). Finite Element Micro-Modeling of Infilled Frames. Electronic J. of Structural Engineering 8: 1-11.

Asteris PG, Antoniou ST, Sophianopoulos DS, Chrysostomou CZ (2011) Mathematical Macromodeling of Infilled Frames: State of the Art. J Struct Eng ASCE 137(12): 1508-1517.

Asteris PG, Cotsovos DM (2012) Numerical investigation of the effect of infill walls on the structural response of rc frames. Open Construction and Building Technology Journal, 6 (1): 164-181.

Asteris PG, Giannopoulos IP, Chrysostomou CZ (2012) Modeling of infilled frames with openings. Open Construction and Building Technology Journal, 6 (1): 81-91.

Asteris PG, Cotsovos DM. Chrysostomou CZ, Mohebkhah A, Al-Chaar GK (2013) Mathematical micromodeling of infilled frames: State of the art. Eng Struct 56: 1905-1921.

Baran M, Sevil T (2010) Analytical and experimental studies on infilled RC frames. Int J Phys Sciences 5(13): 1981-1998.

Bathe KJ, Bouzinov PA (1997) On the constraint function method for contact problems. Computer and Structures 64(5/6): 1069-1085.

Cavaleri L, Di Trapani F (2014) Cyclic response of Masonry infilled RC frames: Experimental results and simplified modeling. Soil Dynamics and Earthquake Engineering 65: 224-242.

Cavaleri L, Di Trapani F, Macaluso G, Papia M (2012) Reliability of code-proposed models for assessment of masonry elastic moduli. Ingegneria Sismica 1: 38-59.

Cavaleri L, Fossetti M, Papia M (2005) Infilled frames: developments in the evaluation of cyclic behaviour under lateral loads. Struct Eng Mech 21(4): 469-494.

Cavaleri L, Papia M (2003) A new dynamic identification technique: application to the evaluation of the equivalent strut for infilled frames. Eng Struct 25: 889-901.

Cavaleri L, Papia M, Macaluso G, Di Trapani F, Colajanni P. (2014) Definition of diagonal Poisson's ratio and elastic modulus for infill masonry walls. Materials and Structures 47(1-2): 239-262.

Chrysostomou CZ, Asteris PG (2012) On the in-plane properties and capacities of infilled frames. Eng Struct 41: 385-402. 
Crisafulli FJ, Carr AJ (2007) Proposed macro-model for the analysis of infilled frame structures. Bull New Zealand Soc Earthquake Eng 40(2): 69-77.

Durrani AJ, Luo YH (1994) Seismic retrofit of flat-slab buildings with masonry infill. Proc. of the NCEER Workshop on Seismic Response of Masonry Infills , Technical report NCEER-94-0004, D.P. Abrams, New York.

Eurocode 8 (2004). Design of structures for earthquake resistance - Part 1: General rules, seismic actions and rules for buildings.

FEMA 356 (2000). Prestandard and commentary for the seismic rehabilitation of buildings.

Fiore A, Netti A, Monaco P (2012). The influence of masonry infill on the seismic behavior of RC frame buildings. Eng. Struct. 44: 133-45.

Flanagan RD, Bennett RM (1999) In-plane analysis of masonry infill materials. Pract. Period. Struct. Des. Constr. 6(4): 176-182.

Flanagan RD, Bennett RM (1999) In-plane behaviour of structural clay tile infilled frames. J. Struct. Eng. 125(6): 590-599.

Jones RM (1975) Mechanics of composite materials. McGraw-Hill, Tokio.

Koutromanos I, Stavridis A, Shing PB, Willam K (2011) Numerical modeling of masonry-infilled RC frames subjected to seismic loads. Computers and Structures 89: 1026-1037

Mainstone RJ (1971) On stiffness and strength of infilled frames. Proceedings of Institution of Civil Engineers 7360s: 57-90.

Mainstone RJ (1974) Supplementary note on the stiffness and strength of infilled frames. Building Research Station, U.K, CP 13/74.

Manos GC, Soulis VJ, Thauampteh J (2011) The behaviour of masonry assemblages and masonry-infilled $\mathrm{R} / \mathrm{C}$ frames subjected to combined vertical and cyclic horizontal seismic-type loading. J Adv Eng Softw 45: 213-231.

Manos GC, Soulis VJ, Thauampteh J (2012) A nonlinear numerical model and its utilization in simulating the in-plane behaviour of multi-story R/C frames with masonry infills. Open Constr Build Technol $\mathbf{J}$ 6:254-277.

Moghaddam HA, Dowling PJ (1987) The state-of-art in infilled frames. ESEE research report 87-2. Imperial College of Science and Technology, London.

NCEER (1994), Workshop on "Seismic response of masonry infills", Technical report NCEER-94-0004, San Francisco.

Papia M, Cavaleri L, Fossetti M (2003) Infilled frames: developments in the evaluation of the stiffening effect of infills. Structural Engineering and Mechanics 16(6): 675-693.

Papia M, Cavaleri L, Fossetti M (2004) Effect of vertical loads on lateral response of infilled frames. Proceedings 13th World Conference on Earthquake Engineering, Vancouver, Canada, No.2931. 
Saneinejad A, Hobbs B (1995) Inelastic design of infilled frames. J. Struct. Eng. ASCE, 121(4): 634-650.

Shing PB, Stavridis A (2014) Analysis of Seismic Response of Masonry-Infilled RC Frames through Collapse. ACI Structural Journal, Special Paper 297-7.

Stafford Smith B (1968) Model tests results of vertical and horizontal loading of infilled frames. Proceedings of American Concrete Institute 65(8):618-625.

Stafford Smith B, Carter C (1969) A method for analysis for infilled frames. Proceedings of Institution of Civil Engineers 7218: 31-48.

Stylianidis KC (2012) Experimental investigation of masonry infilled RC frames. Open Constr Build Technol J 6: 194-212.

Valiasis T, Stylianides K (1989) Masonry Infilled R/C Frames under Horizontal Loading. Experimental Results. European Earthquake Engineering 3: 10-20.

Valiasis T, Stylianides K, Penelis G (1993) Hysteresis Model for Weak Brick Masonry Infills in R/C Frames under Load Reversals. European Earthquake Engineering 1: 3-9.

Valiasis TN, Stylianidis KC (1989) Masonry infills in R/C frames under horizontal loading, Experimental results. European Earthquake Engineering 3: 10-20.

Wang M, He M, Lu J, Huang W (2011) Study on finite element model of infilled walls of steel frames. Advanced Materials Research 250-253: 2424-2427.

Willam KJ, Citto C, Shing PB (2010) Recent results on masonry infill walls. Advanced Materials Research 133-134: 27-30.

Yang W, Ou JP (2010) Finite-element modeling of nonlinear behavior of masonry-infilled RC frames. Journal of Structural Engineering 136(3): 285-296.

Zhai C, Wang X, Li S, Xie L (2011) An improved three-strut model for masonry infills in RC frame structures. Advanced Materials Research 163-167: 4129-4132. 

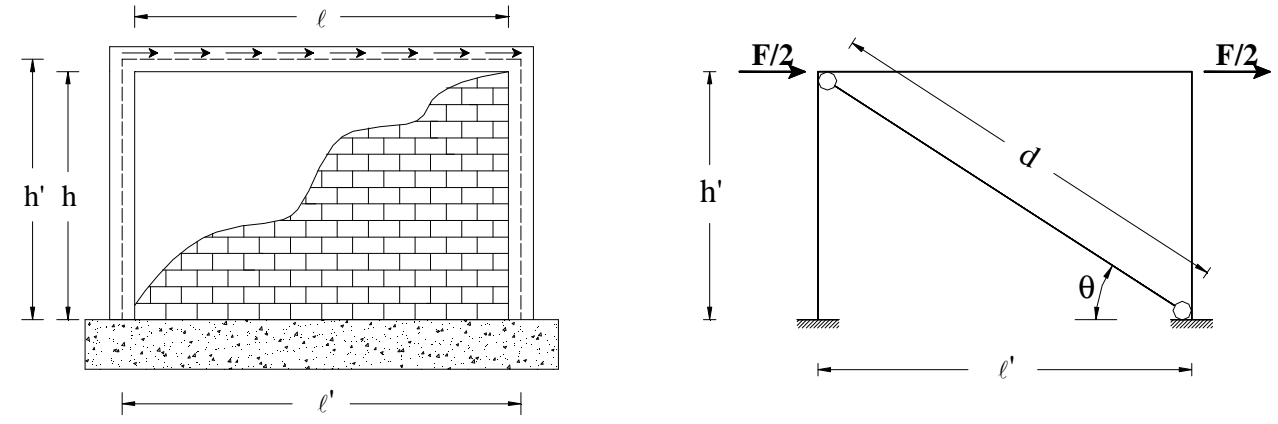

a)

b)

Fig.1 Infilled frame sketch under horizontal load: (a) actual system; (b) macro-model. 


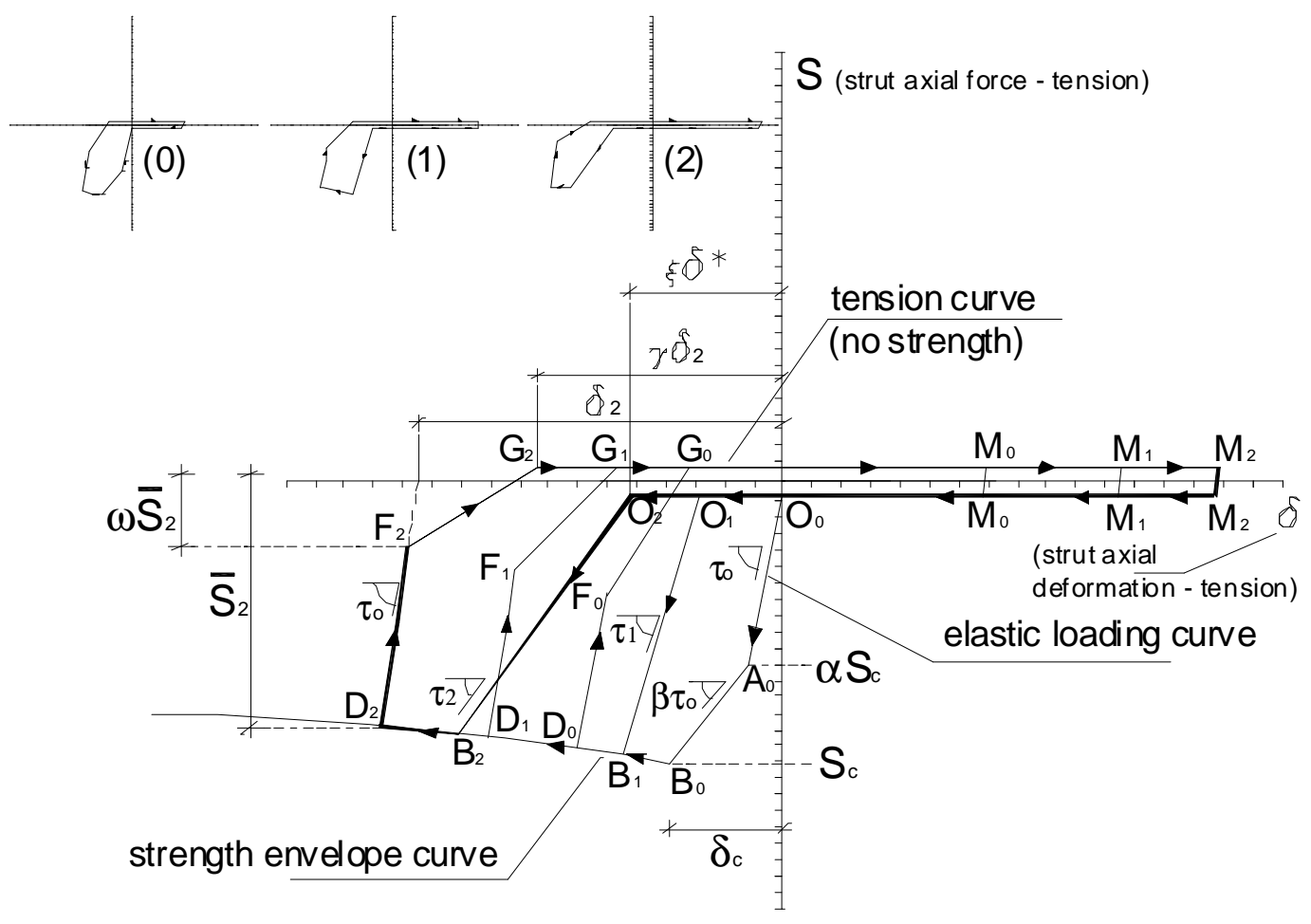

Fig.2 Strut cyclic law proposed in Cavaleri et al. 2005 


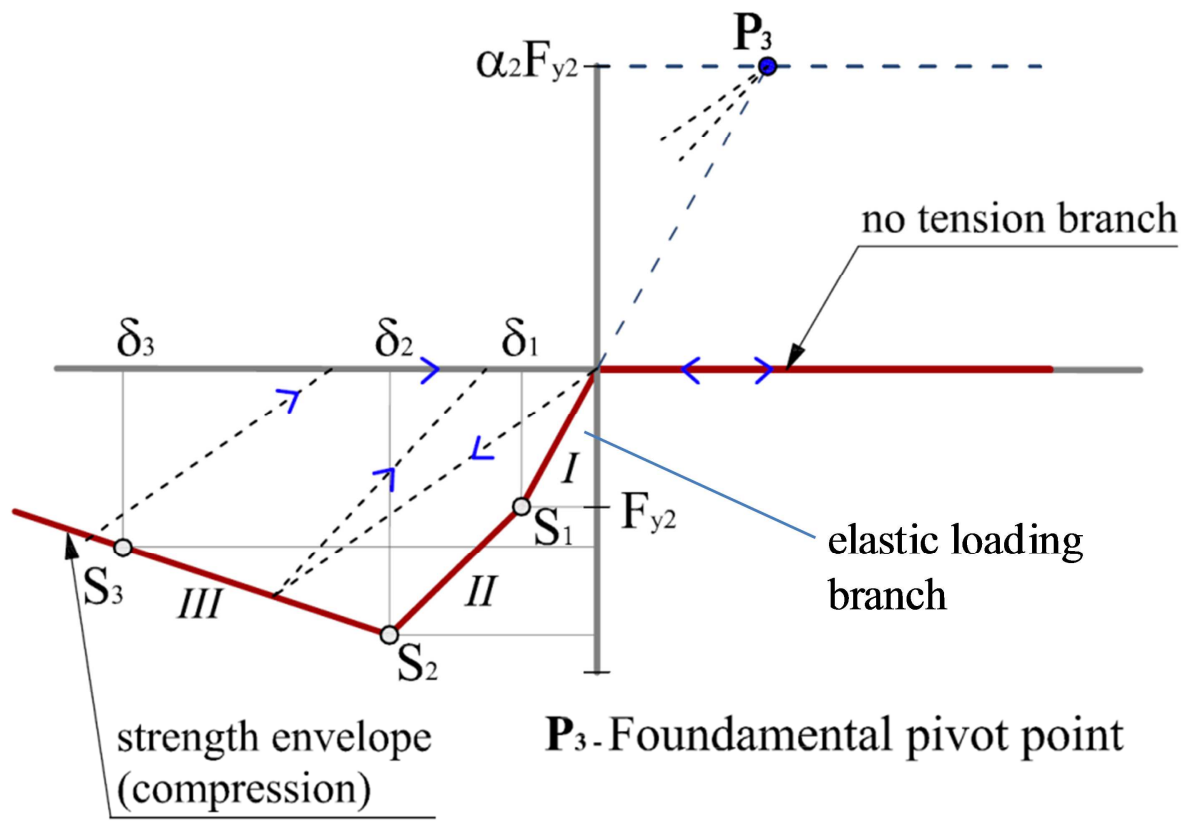

Fig.3 Strut cyclic law proposed in Cavaleri and Di Trapani 2014 

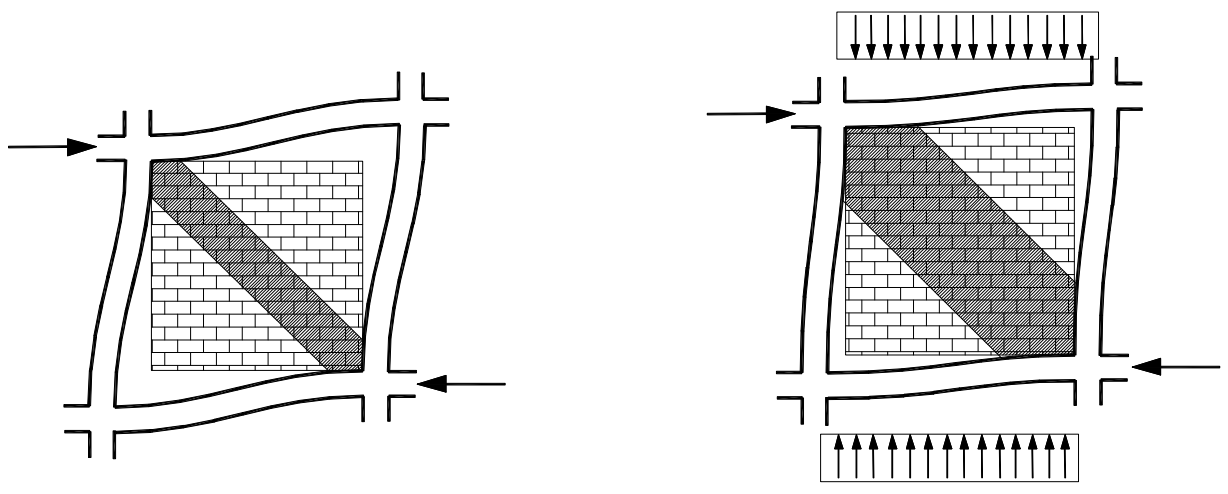

Fig.4. Variation of frame-infill interaction due to vertical load 


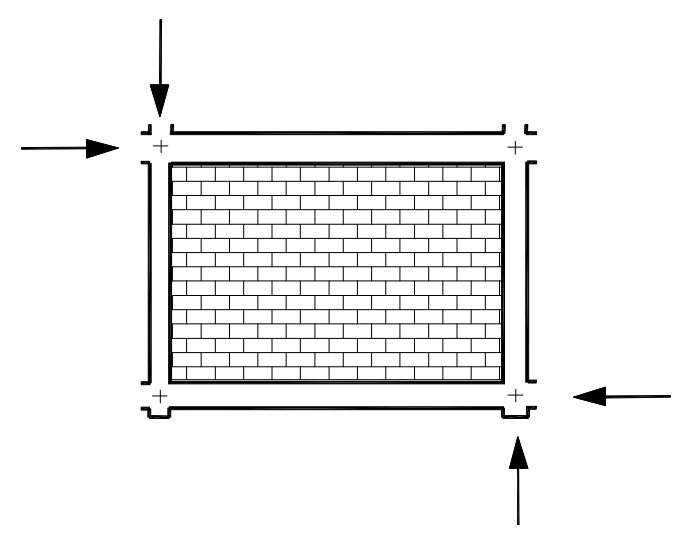

a)

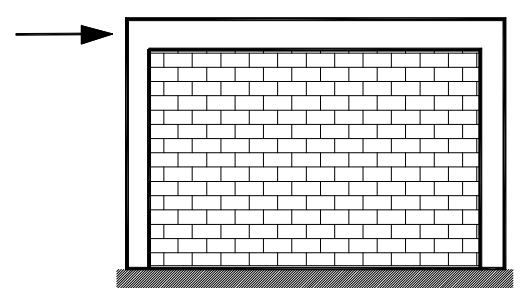

b)

Fig.5 Infilled frame under horizontal load: (a) real scheme, (b) simplified scheme. 


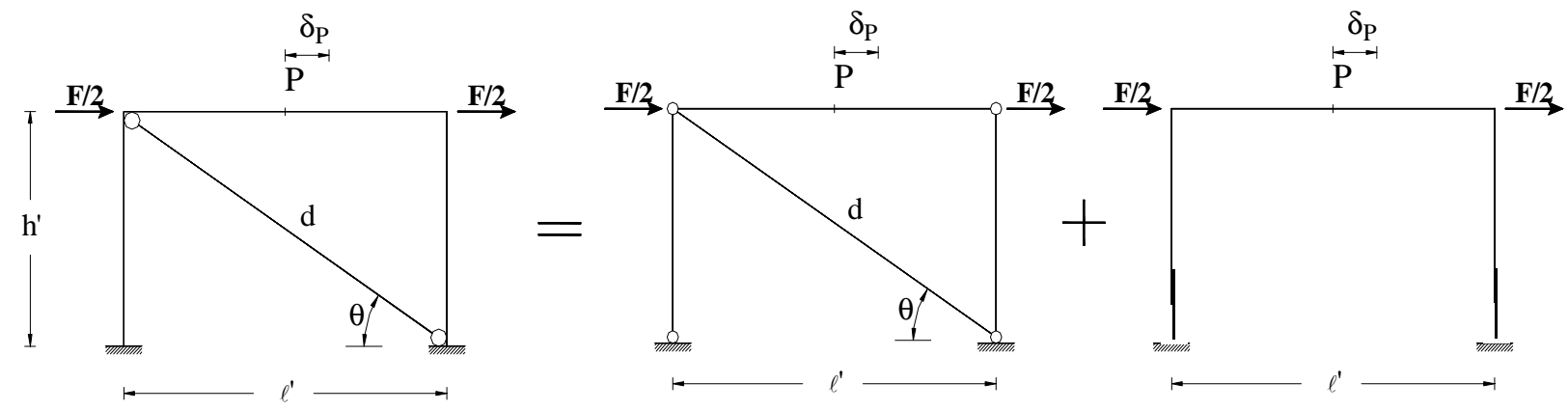
a)
b)
c)

Fig. 6 Decomposition of the macro-model in two schemes 


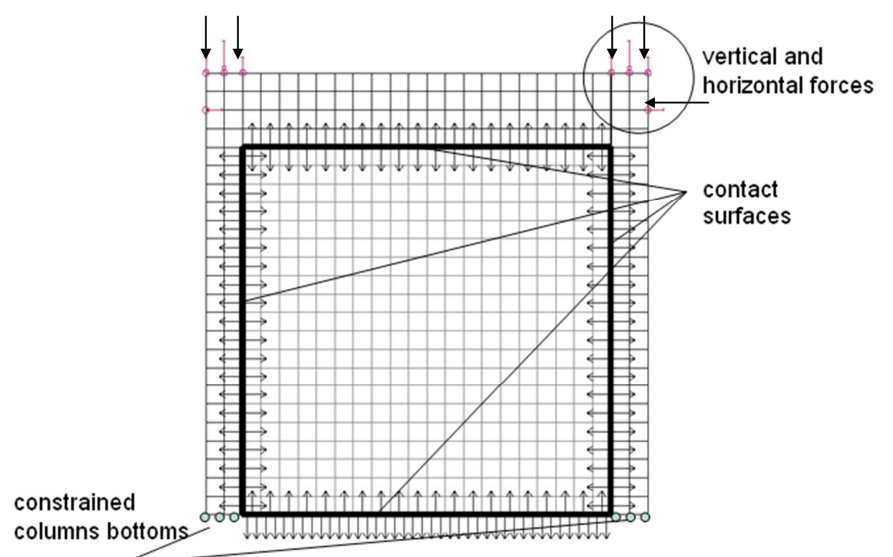

Fig. 7 Finite element model of infilled frame 

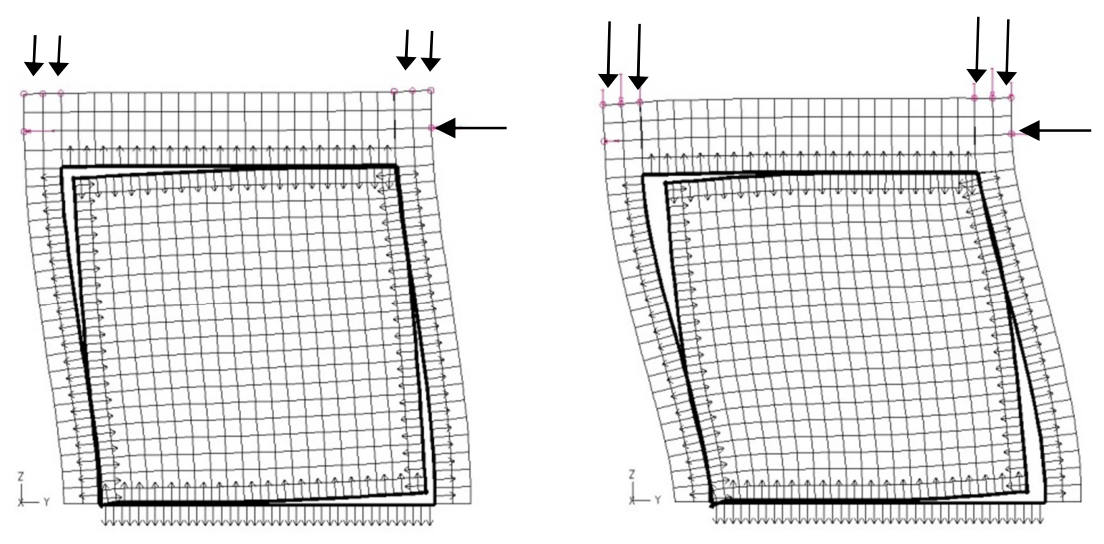

a)

b)

Fig. 8 Variation of the infill-frame contact area for two different vertical load levels: (a)

$\mathcal{E}_{v}=0.00016 ;$ (b) $\varepsilon_{v}=0.00032$ 

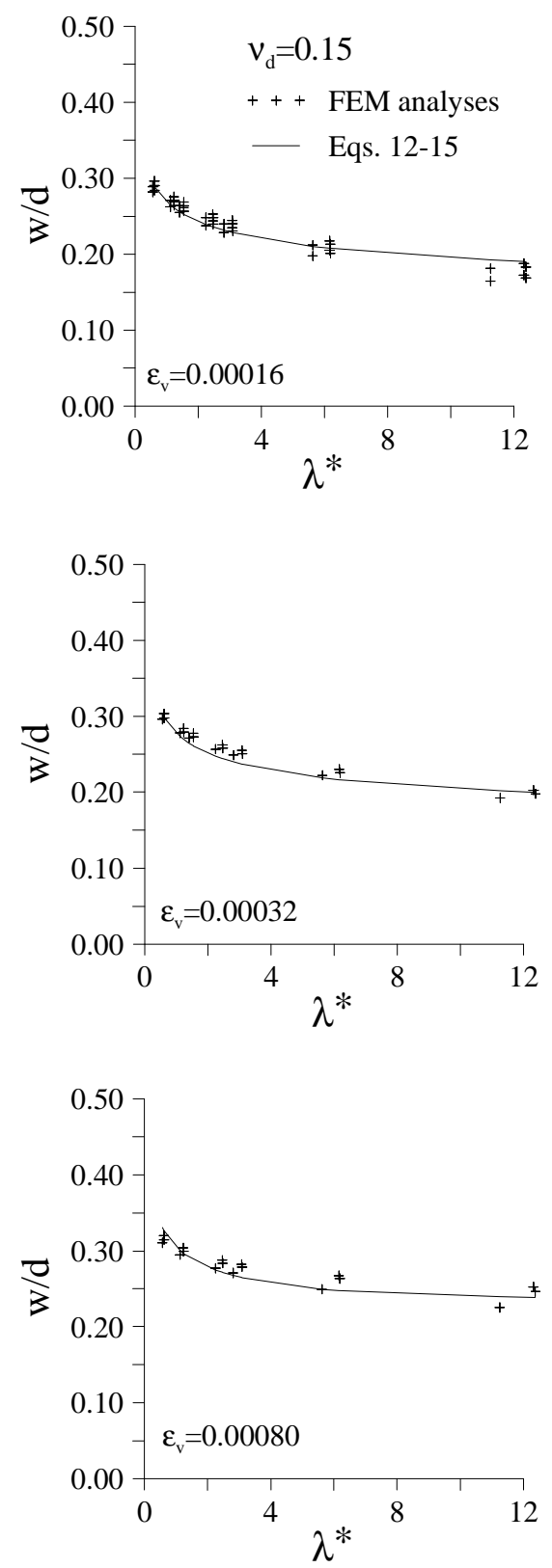

Fig. 9 Results of the FEM analyses and comparison with the proposed analytical curves: square infills; $v_{\mathrm{d}}=0.15$ 

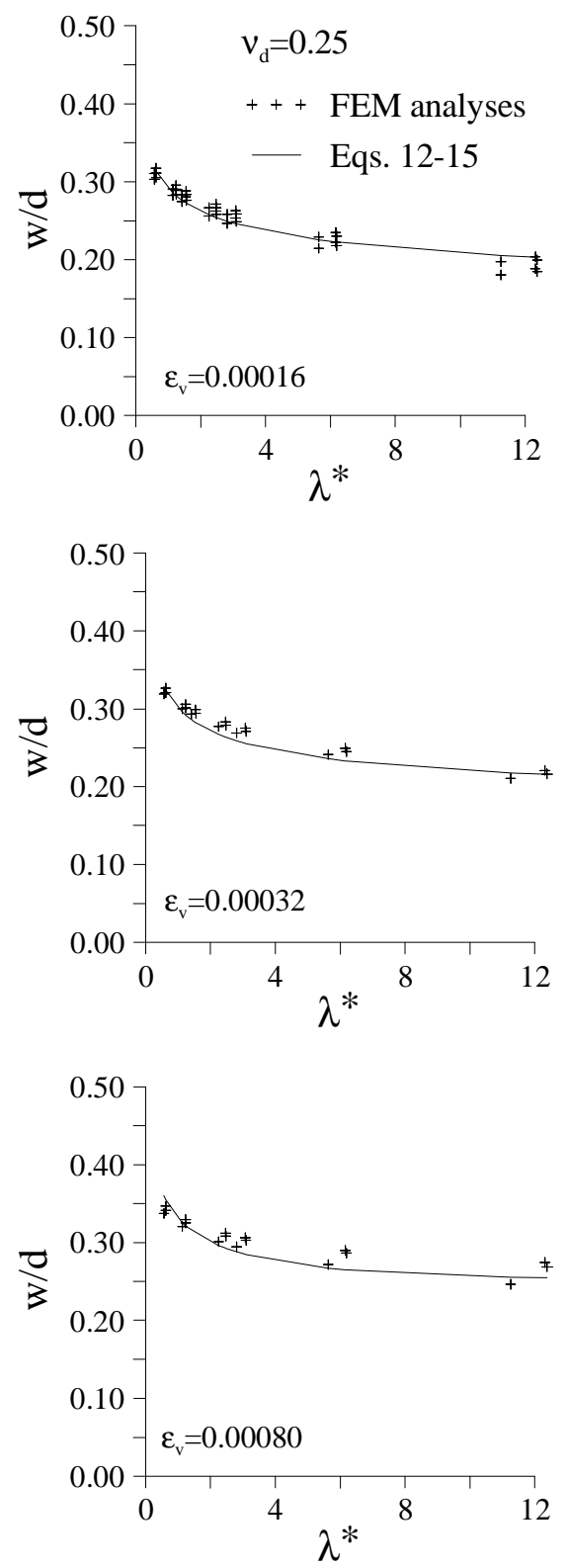

Fig. 10 Results of the FEM analyses and comparison with the proposed analytical curves: square infills; $v_{\mathrm{d}}=0.25$ 

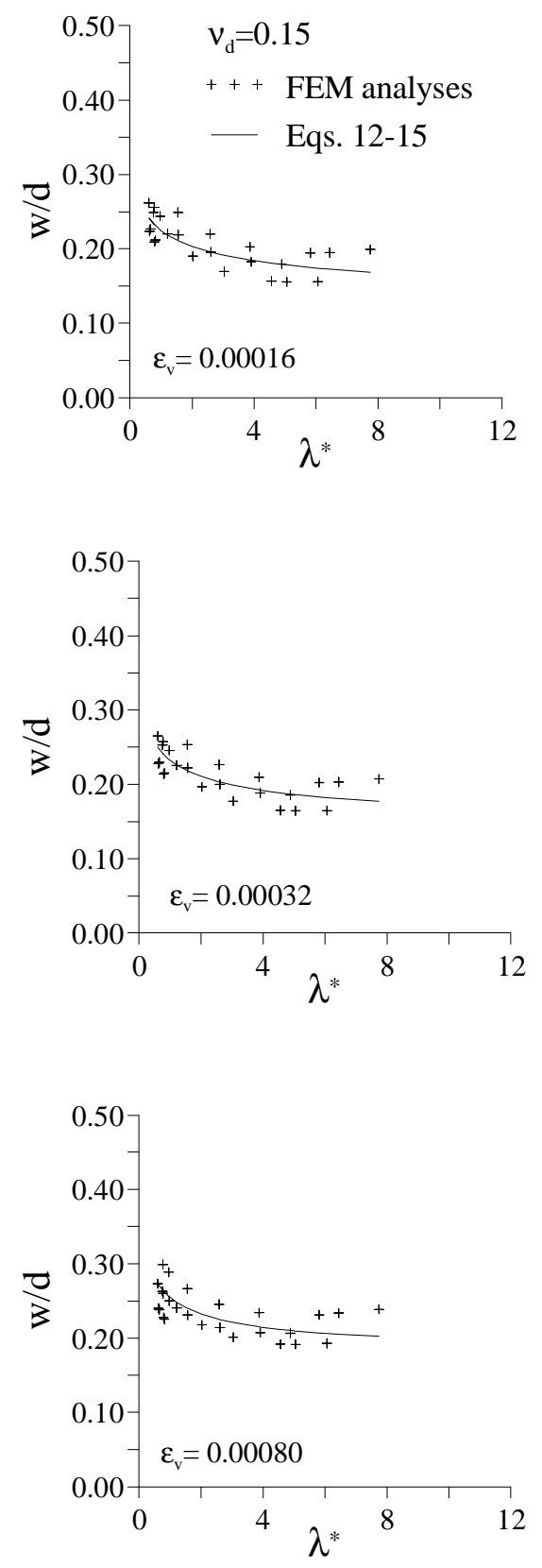

Fig. 11 Results of the FEM analyses and comparison with the proposed analytical curves:

rectangular infills $\frac{\ell}{h}=1.5 ; v_{\mathrm{d}}=0.15$ 

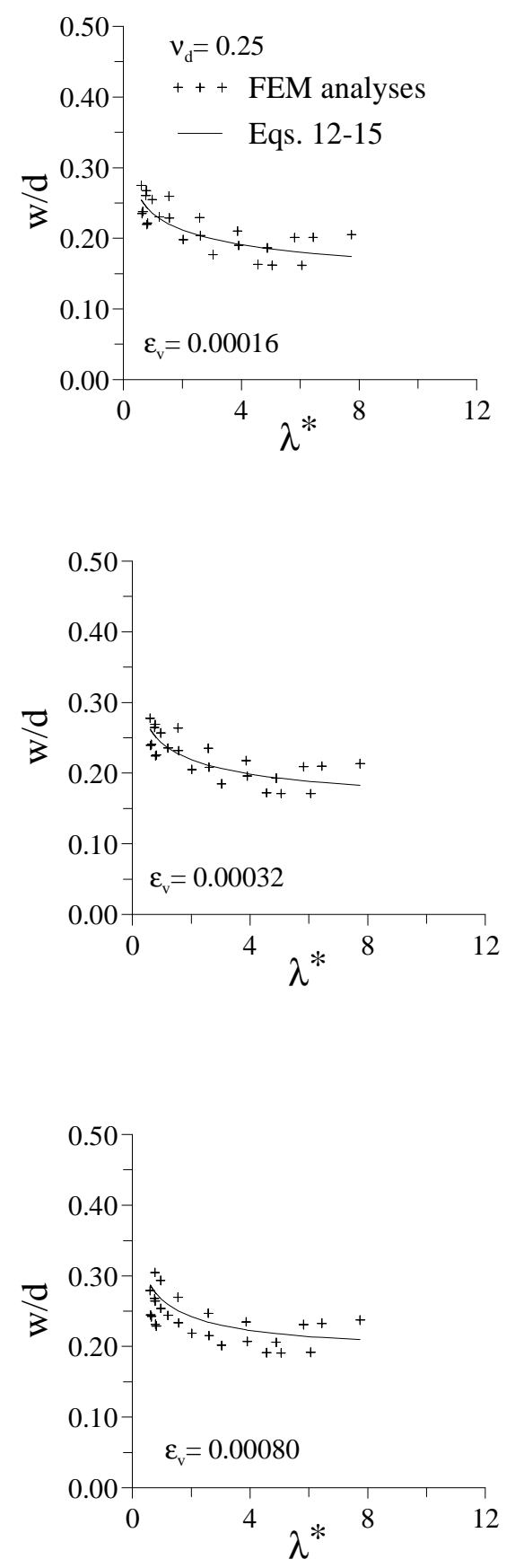

Fig. 12 Results of the FEM analyses and comparison with the proposed analytical curves: rectangular infills $\frac{\ell}{h}=1.5 ; v_{\mathrm{d}}=0.25$ 

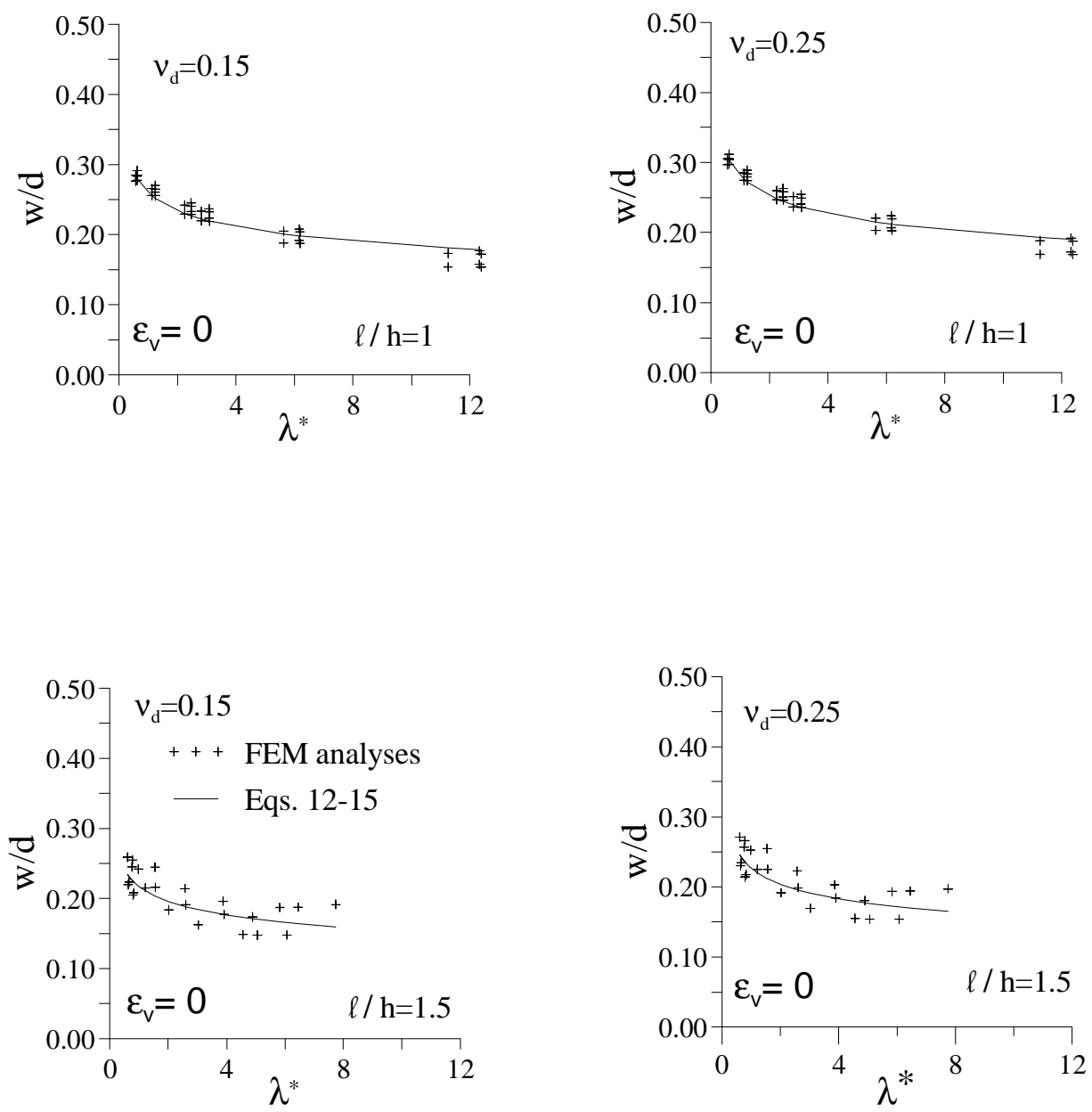

Fig. 13 Results of the FEM analyses and comparison with the proposed analytical curves: no vertical load on infills 


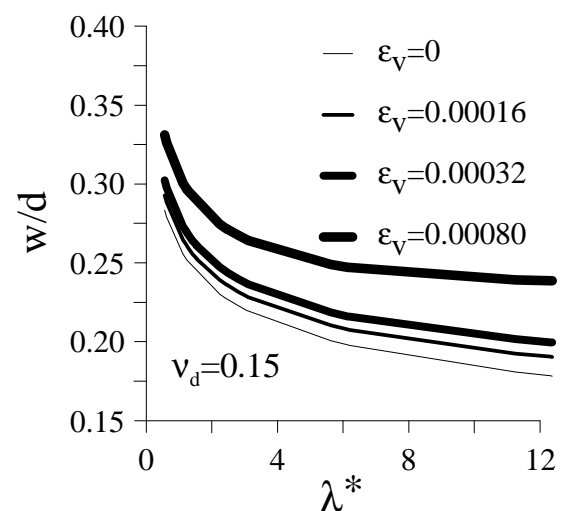

a)

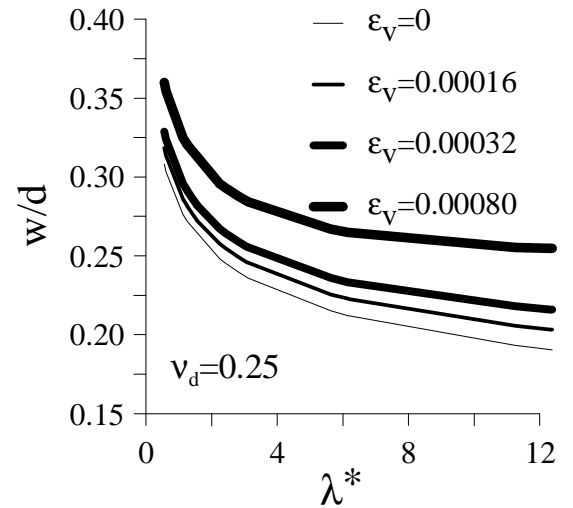

b)

Fig. 14 Proposed analytical curves for different vertical load levels - square infills - (a) $v_{d}=0.15$; (b) $v_{d}=0.25$ 


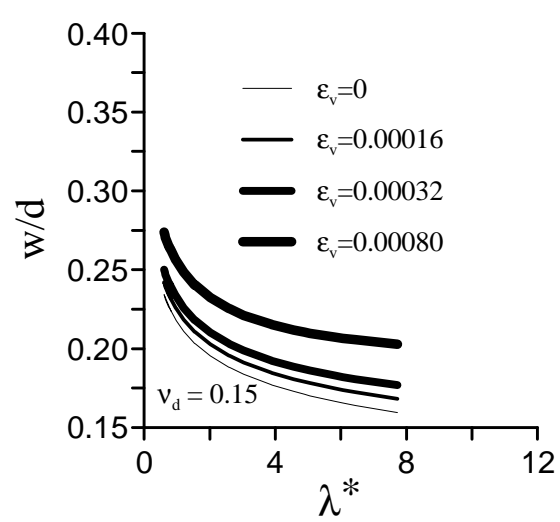

a)

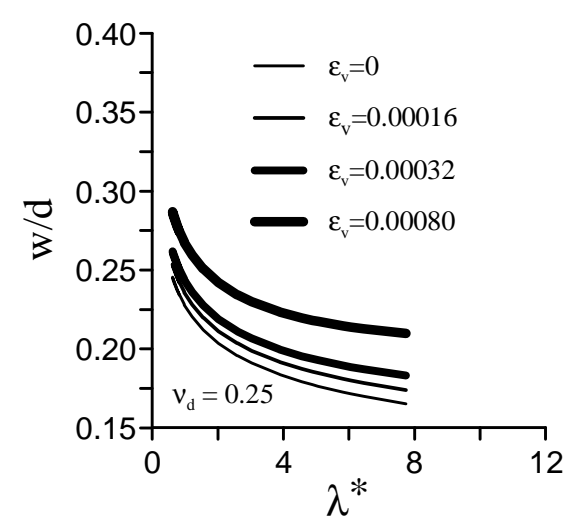

b)

Fig. 15 Proposed analytical curves for different vertical load levels - rectangular infills (a) $v_{d}=0.15 ;$ (b) $v_{d}=0.25$ 